\title{
Do discurso da censura a censura do discurso: o direito à liberdade de expressão nos jornais brasileiros
}

\author{
Andreia da Silva Rocha \\ Universitat Pompeu Fabra \\ E-mail: andreiarocha@gmail.com
}

\begin{abstract}
Resumo
Neste artigo vamos analisar de que forma três grandes jornais brasileiros (o Jornal do Brasil, a Folha de São Paulo e o Jornal do Commercio) apresentaram à sociedade a questão do direito à liberdade de expressão em dois períodos distintos da nossa democracia: primeiro nos anos de 1987 e 1988 durante os trabalhos da Subcomissão da Ciência e Tecnologia e da Comunicação que elaborou o texto que serviu de base ao Capítulo V (Da Comunicação) da Constituição. Em seguida na cobertura dada pelos citados jornais à 1a Conferência Nacional de Comunicação, que em dezembro de 2009 reuniu governo, empre-

de expressão, de imprensa e regulação da comunicação de massa no país. Nosso objetivo é examinar se, e de que maneira, a mídia tem usado o discurso de defesa das liberdades de expressão e de imprensa como instrumento ideológico de proteção e manutenção de seus interesses materiais e simbólicos nos âmbitos político e econômico. Os dados revelam que a maior parte dos grandes veículos deturpa tais conceitos, relacionando quase sempre a não intervenção (estatal ou social) nos negócios da comunicação ao efetivo cumprimento do direito individual à livre expressão.
\end{abstract} sas e sociedade civil em um debate sobre liberdade

Palavras-chave: mídia; liberdade de expressão; liberdade de imprensa; regulação da comunicação.

\begin{abstract}
In this article we analyze how three major Brazilian newspapers (Jornal do Brasil, Folha de São Paulo and Jornal do Commercio) presented to society the issue of the right to freedom of expression in two distinct periods of our democracy: first in 1987 and 1988, during the work of the Subcommittee on Science and Technology and Communication, which prepared the text that served as the basis for Chapter $\mathrm{V}$ (Communication) of the Constitution. Then, in the coverage given by the newspapers mentioned to the

1st National Communication Conference, which in December 2009 brought together government, companies and civil society in a debate on freedom of expression, press and mass communication regulation in the country. Our objective is to examine how the media used the discourse to defend the freedoms of expression and of the press as an ideological instrument of protection and maintenance of their material and symbolic interests in the political and economic spheres. The data show that most large vehicles
\end{abstract}

Data de submissão: 31/05/2017. Data de aprovação: 30/06/2017.

A Revista Estudos em Comunicação é financiada por Fundos FEDER através do Programa Operacional Factores de Competitividade - COMPETE e por Fundos Nacionais através da FCT - Fundação para a Ciência e a Tecnologia no âmbito do projeto Comunicação, Filosofia e Humanidades (LabCom.IFP) UID/CCI/00661/2013.
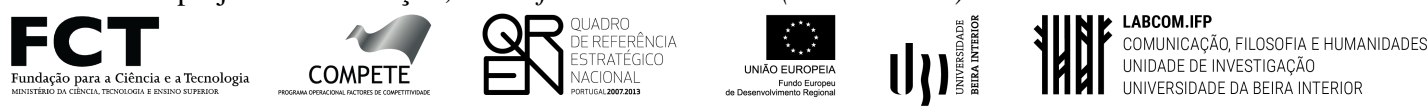
misrepresent such concepts, almost always relating non-intervention (state or social) in the business of communication with the effective realization of the individual right to freedom of expression.

Keywords: media; freedom of expression; freedom of the press; regulation of communication.

\section{Introdução}

Pós quase 20 anos de um regime que reduziu quase a zero as garantias fundamentais e as

liberdades individuais no Brasil, a expectativa sobre a completa abolição da censura foi o fio condutor dos debates em torno dos direitos à liberdade de expressão e de imprensa na Subcomissão da Ciência e Tecnologia e da Comunicação, que ficou responsável pela elaboração do Capítulo V (Da Comunicação) na Constituição Brasileira de 1988.

As "batalhas" travadas entre "conservadores" e "progressistas" durante as reuniões das comissões temáticas na Assembleia Nacional Constituinte em torno do tema da comunicação foram acompanhadas de perto pelo sociólogo e jornalista Venício Lima, que na época atuou como assessor dos relatores Cristina Tavares, na Subcomissão, e de Artur da Távola, na Comissão. Sobre as questões "discutidas" durante as reuniões Lima escreveu:

Algumas foram consensuais e sobre elas não havia disputa. Por exemplo: a garantia da liberdade de expressão através do total banimento da censura de qualquer natureza. Outras, sobretudo aquelas com implicações diretas na democratização das comunicações, encontraram enorme resistência. Por exemplo: o uso de concessões de radiodifusão como moeda de barganha política; a criação de um órgão regulador autônomo com poderes para outorgar, renovar e cancelar concessões de emissoras de rádio e televisão; a regionalização da produção jornalística, cultural e artística; a concentração da propriedade e a "propriedade cruzada"de diferentes veículos de comunicação; o equilíbrio entre os sistemas privado, público e estatal de comunicações (Lima, 2008).

No balanço final do processo, o saldo de ganhos pendeu bem mais para o lado dos empresários da radiodifusão e a promulgação da nova Carta acabou consolidando um modelo de comunicação que priorizou o mercado e o lucro.

Mais de 20 anos depois, precisamente em 17 de abril de 2009, penúltimo ano de governo do petista Luis Inácio Lula da Silva, o diário oficial da União tornava pública a realização da $1^{\text {a }}$ Conferência Nacional de Comunicação. A comissão organizadora do evento seria composta por 26 membros, sendo 16 da sociedade civil e 10 do poder público. Dos 16 membros da sociedade civil, 8 eram vinculados a entidades empresariais, ou seja, exatamente a metade do total da representação deste segmento. Tais números, em nosso entender, mostravam que desde o início a intenção do governo era buscar o equilíbrio no debate entre sociedade civil e o empresariado. Mas, tendo entre seus objetivos a discussão de temas como regulação econômica e o combate aos oligopólios, a conferencia, claro foi intensamente atacada pela grande mídia 8 que acusavam o governo de querer trazer de volta a censura e os empresários do setor passaram a ameaçar se retirar do evento. 
Atuando como "bombeiro" o governo buscava atenuar os embates e acabou fazendo inúmeras concessões na tentativa de manter os empresários no evento. Tais esforços, no entanto, não foram suficientes e no dia 13 de agosto, seis das oito entidades empresariais anunciaram a decisão de deixar a comissão organizadora. Apesar das tensões e ausências, a conferencia aconteceu (de 14 a 17 de dezembro de 2009) e ao fim de três dias de trabalho foram colhidas mais de 600 propostas que deveriam servir de referência para projetos com foco na regulação e democratização do setor das comunicações no Brasil.

Analisando os aspectos qualitativos e quantitativos das notícias retiradas dos jornais Folha de S. Paulo, Jornal do Brasil e Jornal do Commercio procuraremos compreender como esses veículos se apropriaram da discussão em torno da importância das liberdades de expressão e de imprensa nesses dois importantes momentos para a comunicação social no país. De que forma enquadraram e levaram o assunto ao público e, por fim, como seus discursos contribuíram para a construção da realidade social brasileira é o que vamos observar neste artigo.

\section{Corpus e metodologia}

Para analisar de que forma alguns dos grandes veículos de comunicação de massa brasileiros vêm apresentando à sociedade o discurso da liberdade de expressão e da liberdade de imprensa escolhemos observar três dos principais jornais do país: o Jornal do Brasil (JB) do Rio de Janeiro, a Folha de São Paulo (FS), do Estado que lhe dá nome e o Jornal do Commercio de Pernambuco (JC).

O material a ser estudado corresponde a um total de 88 textos, entre notícias, reportagens e editoriais publicados entre os períodos de janeiro de 1987 a dezembro de 1988 e de agosto de 2009 a março de 2010. O primeiro intervalo corresponde ao período em que foram travadas as discussões das comissões e subcomissões que trataram da Comunicação Social na Assembleia Nacional Constituinte. O segundo analisa nos veículos selecionados a repercussão nos três meses antes e três meses depois da $1^{a}$ Conferência Nacional de Comunicação (Confecom) ocorrida em dezembro de 2009. A delimitação de tais períodos foi ancorada no principio da proximidade temporal como fator de noticiabilidade jornalística.

$\mathrm{Na}$ Folha os textos foram retirados das editorias 'Primeiro Caderno', 'Brasil', 'Editoriais', e 'Política". No JB foram pesquisadas as sessões 'Política' 'Nacional' 'País' e 'Editoriais' e no Jornal do Commercio a busca se concentrou nas editorias 'Capa Dois', 'Editorial', 'Política', 'Nacional' e 'Brasil'. Importante ressaltar que a pesquisa no JC no ano de 1987 possui um hiato de 53 dias, período em que devido ao atraso no pagamento dos salários e às péssimas condições de trabalho, os funcionários do jornal fizeram uma greve geral e retiraram o impresso das bancas de 23 de fevereiro a 18 de abril.

Para a análise vamos utilizamos dois enfoques metodológicos: pesquisa bibliográfica e Análise do Discurso. No primeiro caso, buscamos o diálogo com importantes autores das Ciências Sociais a fim de entender e contextualizar as tensões existentes entre a sociedade e o campo dos media. Através da Análise do Discurso tentaremos identificar o processo ideológico inerente à constituição da linguagem e como os veículos objetos de nossa investigação se apropriaram da discussão em torno da importância das liberdades de expressão e de imprensa e de que maneira 
seus discursos contribuíram para a construção da realidade social dos momentos históricos analisados.

\section{Marco Teórico: liberdade de expressão, discurso e formação do consenso}

Como instituição responsável pela mediação dos processos comunicativos, a mídia ocupa um lugar de fala que lhe permite se colocar e se legitimar como instância representativa dos valores

sociais. É com base neste papel (conferido a ela pela própria sociedade), que seus discursos são autorizados e seu poder de construir, definir e transmitir significados, validado. Os meios de comunicação devem ser, portanto, alvos de diferentes exigências que previnam e detectem possíveis patologias no exercício do poder e garantam a pluralidade tanto no que concerne à extensão de cobertura e acesso, como no que diz respeito ao conteúdo, vozes e ideologias. Por isso, podemos afirmar que as liberdades de expressão e imprensa são fomentadoras de Estados e processos realmente democráticos, transparentes e participativos.

Mas, a frequente confusão que se faz entre os dois mais importantes conceitos na discussão sobre o direito à comunicação enseja que dediquemos parte do nosso texto a procurar as semelhanças e divergências entre as liberdades de expressão e de imprensa.

Inúmeros documentos históricos abordam os direitos à liberdade de expressão e de imprensa como sendo direitos distintos (Carta das Nações Unidas (1945), Declaração Universal dos Direitos Humanos (1948), Pacto Internacional sobre Direitos Civis e Políticos (1966)). Na maior parte deles, o primeiro se trata do direito individual de se expressar livremente, à liberdade pessoal de exteriorizar e compartilhar ideias e pensamentos. Já o segundo seria uma liberdade "social" condicionante para a existência da individual expressão, porém equacionada pelos veículos de comunicação/imprensa (Lima, 2010, p.24).

Partindo dessa ideia, pode-se afirmar que o direito à livre expressão é o sustentáculo de todos os outros direitos, entre eles o da imprensa livre. Assim, a liberdade de imprensa não pode nem deve ser entendida como um "tipo especial" de liberdade de expressão, mas como uma espécie de "subproduto" da mesma, intimamente associada à coletividade e viabilizada pelos meios de comunicação. Liberdade de expressão e liberdade de imprensa são, portanto, liberdades distintas.

Porém, entre nós é corriqueiro não apenas o emprego das duas expressões de forma equivocada (como se fossem equivalentes) como ainda a ideia de que ambas as liberdades podem ser transferidas do indivíduo para a sociedade e desta para as empresas de comunicação. Nenhuma lei, ordem ou declaração, no entanto, aponta a possibilidade das empresas de comunicação tutelarem o cidadão no exercício desse direito. Citando o artigo 19 da Declaração Universal dos Direitos Humanos (1948) o professor Kaarle Nordenstreng é enfático:

O sujeito dos direitos humanos e das liberdades fundamentais não é uma instituição chamada imprensa ou a mídia, mas um ser humano individual. [...] a frase 'liberdade de imprensa' é enganosa na medida em que ela inclui uma ideia ilusória de que o privilégio dos direitos humanos é estendido à mídia, seus proprietários e seus gerentes, ao invés de ao povo para expressar sua voz através da mídia [...] nada no artigo 19 sugere que a instituição da imprensa tem qualquer direito de propriedade sobre esta liberdade (citado em Lima, 2009, p. 25). 
Trata-se, portanto, de direito inviolável e inalienável. Assim colocado, não deveria haver dúvidas e discussões quanto ao seu cumprimento. Mas, em uma sociedade capitalista, globalizada e norteada por modelos neoliberais, o domínio e usufruto deste direito passaram a estar também imersos na lógica da acumulação de riquezas, disputa pelo poder simbólico e luta pela hegemonia.

\subsection{Liberdade de expressão $x$ censura}

A censura promovida pelos poderes constituídos foi, durante a maior parte da história da comunicação mediada, a principal forma de restrição da liberdade de expressão. Dessa maneira, a recusa e o medo da censura se constituíram como elementos base da evolução doutrinal e da luta por esse direito.

Após 24 anos de um regime de exceção, a comunicação social brasileira ganhou na nova Constituição (1988) um capítulo especial para si e nele a censura foi oficialmente proibida. No entanto, tal palavra continua amplamente invocada dentro do debate político brasileiro, principalmente quando o assunto envolve questões relativas à liberdade de expressão, de imprensa e à regulação das comunicações.

Atualmente o termo é usado de maneira seletiva e ao mesmo tempo indiscriminada para designar as mais diversas situações, “...desde a promulgação de um plano contendo diretrizes de políticas governamentais, passando pela criação de um órgão fiscalizador da profissão de jornalista, até a representação feita por um órgão do governo federal ao CONAR..." (Carvalho, 2012, p. 54).

Tal confusão é principalmente promovida pelos próprios veículos de comunicação que têm na ameaça da volta à censura e do fim da liberdade de imprensa o escudo ideal de proteção para seus interesses políticos e econômicos. Ao "satanizar" e rotular como censura toda e qualquer proposta de políticas públicas que caminhem a favor da democratização dos meios e do combate aos oligopólios, os grandes grupos de mídia garantem que grande parte da sociedade não perceba que a censura econômica (promovida pela atual concentração de meios nas mãos de poucos) pode ser tão ou mais nociva para a consolidação do processo democrático quanto a censura estatal.

Nesse sentido, Carvalho (2012) corrobora que a problemática da censura não termina com o fim da sua prática institucional, ou seja, o fim da repressão estatal não traz a liberdade como uma decorrência natural. $\mathrm{O}$ autor afirma que "os demais mecanismos sociais de interdição sobre a expressão das ideias podem, muito bem, continuar presentes, ainda que sob novas roupagens, gerando efeitos semelhantes à interferência direta de uma burocracia centralizada" (Carvalho, 2012, p. 69).

A despeito do não uso de práticas expressamente coercitivas, as empresas privadas de comunicação se constituem hoje como censores potenciais da livre circulação de ideias na esfera do discurso público. Tanto pela forma de atuação dos veículos (promovendo o silêncio e a interdição do livre debate sobre inúmeros temas) como pela maneira como tais empresas se estruturam (sujeição à concorrência, dependência de investidores e o lucro como objetivo).

Sob o peso dos interesses comerciais, conteúdos e notícias são moldados para encaixe em uma estrutura onde as forças políticas e econômicas são predominantes e determinantes. Assim, “... um dos paradoxos é que a competição, sempre apontada como uma das pré-condições da liberdade, 
tem o efeito, nos campos de produção cultural controlados por interesses comerciais, de produzir uniformidade, censura e, mesmo, conservadorismo" (Bourdieu, 2005, p. 44).

\subsection{Liberdade expressão e a seleção das fontes}

Sendo a fala relatada o principal meio moderno de conferir autenticidade e credibilidade ao texto jornalístico, a seleção das fontes que terão voz na narrativa do fato torna-se um importante operador discursivo. No processo de construção e "venda" da notícia, a escolha (seja ela consciente ou inconsciente) da(s) voz(es) a ser(em) priorizada(s) no relato termina por revelar também a maneira como o locutor deseja guiar seu texto, os efeitos de sentido pretendidos por ele.

Esse "posicionamento" pode se revelar através de inúmeras intervenções e transformações no que é dito pela fonte. A seleção de uma palavra ou de um trecho em particular, as alterações lexicais (por exemplo, transformar uma dúvida em afirmação), a utilização de termos condicionais como "acredita", "de acordo com" também possuem grande importância para o efeito de sentido que se pretende dar ao discurso. Ou seja, a organização esquemática de informações e fontes, o estilo, as orientações lexicais e retóricas, os tópicos e pressuposição são elementos que afetam diretamente o discurso. Esse não é, portanto, um processo neutro, já que escolher uma palavra significa silenciar outra, enfatizar um ângulo significa esconder o outro, destacar determinada voz significa abafar outra. Na arena onde ocorre a disputa pelo poder de dar significado às coisas, mudar as palavras implica mudar as próprias coisas (Bourdieu, 2003).

Em um ambiente extremamente desigual como é o da sociedade capitalista, a garantia da liberdade e da igualdade passa também pela soberania do direito de fala em igualdade de tempo e espaço (Chauí, 2012). Essa garantia mantém relação direta não só com o bom funcionamento do campo político, mas também com as atividades dos sistemas econômico, cultural, religioso, científico, artístico, desportivo, etc. "Todos eles devem se apresentar estrutural e comunicativamente abertos, configurando espaços de confrontação competitiva e interação crítica das concepções, ideias, opiniões, interesses e preferências, [...] alicerçados na autonomia individual e na descentralização da autoridade" (Machado, 2002, p.16).

Estando, assim, a garantia do direito à comunicação diretamente ligada à própria noção de democracia, um espaço comunicacional onde não há igualdade de vozes está violando não somente o princípio democrático da isonomia (todos são iguais perante a lei), mas também o princípio que a democracia grega nomeou de isegoria: o direito de todos de expor, em público, suas opiniões em condições de igualdade.

No entanto, basta uma rápida olhada nos conteúdos veiculados pela maioria dos grandes jornais brasileiros para perceber que grande parte da produção de notícias se constrói sob discursos de ausência. Na deslegitimação discursiva de alguns atores sociais a grande mídia segue publicando a opinião de segmentos específicos como se consenso fosse, ampliando a fenda entre sociedade civil e poder público e impedindo o debate democrático e dialógico, próprio e indispensável às democracias mais avançadas. 


\section{Resultados}

\subsection{Liberdade de expressão, liberdade de imprensa e liberdade de empresa}

Ao observar a maneira como os três jornais aqui analisados fizeram alusão ao direito à liberdade de expressão nos dois períodos em questão, foi possível categorizar a maneira como esses meios representaram o tema em dois modelos básicos: no primeiro a liberdade de expressão é tratada como se sinônimo da liberdade de imprensa, no segundo observa-se a intenção de criar equivalência entre esse direito ao da livre iniciativa empresarial. Vejamos:

\subsubsection{Liberdade de expressão representada como sinônimo de liberdade de imprensa}

Trata-se da histórica confusão promovida pela mídia entre os conceitos de liberdade de expressão e de imprensa. Implicitamente a mídia faz o deslocamento de um direito que é somente do cidadão para as empresas de comunicação e trata as liberdades de expressão e de imprensa como se equivalentes fossem.

Nas matérias que abordam o assunto, raramente os dois conceitos são apresentados como deveriam ser: a liberdade de expressão como o direito de cada pessoa e a de imprensa como o exercício de uma função pública. Muito pelo contrário: defende-se o direito dos grandes empresários gerirem o setor da comunicação da forma que bem lhes convier como sendo a única maneira de assegurar o direito à expressão da sociedade como um todo. No trecho abaixo, o diretor do Jornal do Brasil, José Antônio do Nascimento Brito promove a clássica equivalência entre os dois conceitos falando em livre manifestação na imprensa.

Em palestra no $6^{\circ}$ Congresso Brasileiro e no $1^{\circ}$ Congresso Latino-Americano de Jornais do Interior, ontem, em Gramado, o diretor-executivo do Jornal do Brasil, José Antônio do Nascimento Brito, também presidente da Associação Nacional de Jornais, afirmou que "na Constituinte, o conceito de liberdade de expressão deve ser bem amplo; queremos liberdade de imprensa, e ponto final". Na sua opinião, todas as demais questões relativas ao direito à livre manifestação na imprensa "devem ser decididas por lei ordinária" (ANJ reivindica ampla liberdade para a imprensa, 1987).

Ora, sabemos que de forma alguma quando fala em livre manifestação na imprensa Nascimento Brito não se refere à possibilidade de todos os cidadãos usarem a imprensa para expressar suas ideias democraticamente, mas sim reivindica um "trânsito" completamente livre para que o empresariado usufrua dos veículos da forma que acharem melhor.

\subsubsection{Liberdade de expressão representada como liberdade comercial/empresarial}

Dentro da mesma lógica que busca confundir o direito fundamental à expressão com o direito dos conglomerados comunicacionais atuarem sem limites políticos e financeiros, os jornais materializam e tentam forçar a aceitação social do que nomeou de "liberdade de expressão comercial". 
Tratando tal termo como se jurídico fosse, o empresariado busca esvaziar o real sentido da liberdade de expressão estabelecendo uma inexistente relação entre este direito e a ausência total de restrições econômicas à atividade midiática. É o caso dos dois trechos em destaque (o primeiro uma notícia, o segundo um editorial) nos quais a postura de condicionar o exercício da liberdade de expressão ao princípio neoliberal do "mais mercado" fica bem clara.

(02)

A liberdade de imprensa, assegurada pela livre iniciativa e pela economia privada, foi defendida pelo presidente da ANJ (Associação Nacional de Jornais), José António do Nascimento Brito, na reunião de ontem da subcomissão de Ciência, Tecnologia e Comunicação, da Assembleia Nacional Constituinte. - Entendemos que a Constituição do país deve estar livre das normas que, em nome da segurança do Estado e da moralidade pública, submetem a liberdade de expressão a limites e ressalvas - declarou o presidente da ANJ (ANJ defende imprensa livre na constituinte, 1987).

A Constituinte agora é a oportunidade para que o Brasil - que já deu demonstração de que o capital estrangeiro é uma alavanca para a economia saltar uma etapa - consolidar a ideia de desenvolvimento e de democracia, e não para restringir a liberdade de iniciativa, que é a matriz dos cerceamentos políticos.

De que maneira pode ser social um regime que, em vez de acreditar na liberdade, recorre ao Estado como patrono do progresso e pai dos cidadãos? A sociedade não é uma parcela, mas o todo: do outro lado está o Estado, com sua burocracia e tudo que o serve (Projeções do atraso, 1987).

Através desse enfoque se propaga o entendimento de que a liberdade de expressão está em uma permanente batalha contra a sanha regulatória de um Estado que está sempre à espreita aguardando a oportunidade de mergulhar o país novamente no obscurantismo. É assim que qualquer debate em torno de propostas de regulamentação para o setor das comunicações é atacado pelos grandes veículos e apresentado à opinião pública como tentativa do Estado de cercear a liberdade de expressão e de imprensa e ameaçar a própria democracia. Propagando de maneira exaustiva a equação regulamentação = cesura, ela dissemina a ideia do Estado-tirano e apresenta a si mesma como única e grande defensora do direito do cidadão à livre expressão.

\subsubsection{O "fantasma" da censura}

Em todos os momentos em que sentiu que seus negócios estavam "ameaçados" as empresas midiáticas lançaram mão da memória interdiscursiva da censura e da pesada carga simbólica que ela ainda possui no imaginário dos brasileiros para reproduzir sua própria versão sobre o que significam liberdade de expressão, liberdade de imprensa e regulação econômica/social.

Nos trechos abaixo podemos identificar claramente o uso de operadores discursivos que buscam ressaltar o perigo iminente que sistemas de controle jurídico ou social podem representar para a liberdade de expressão. Textos que buscam confundir o leitor e convencê-lo de que esse sen- 
timento de "preocupação" deve ser compartilhado por todos que não desejam abrir mão de uma democracia que foi arrancada à força do Estado, que é tirano e controlador por natureza.

(04)

[...] Sua aclamação popular (do então presidente Lula), porém, dá ensejo para que o governo venha flertar com tentações autoritárias, bem ao gosto dos "neoestatólatras". Parece ser este o caso da Confecom - a conferência organizada por Franklin Martins para discutir a regulação das comunicações no país. [...]Sob a retórica da democratização, o que se busca é esvaziar a imprensa independente, aquela que fiscaliza e dá azia em Lula todas as manhãs (No vácuo de Lula, 2010).

[...]Os debatedores alertaram os brasileiros para o fato de as medidas de controle e censura da mídia em seus países terem começado sob o pretexto da necessidade de incrementar a responsabilidade social dos veículos de comunicação. (Fórum crítica "controle social"da mídia, 2010).

(06)

Mas - concluiu Civita - se isso acontecer (a criação do Conselho Nacional de Comunicação com um marco regulatório) estaria garantido o funeral, sem maior pompa, da liberdade de expressão e de todas as demais liberdades. O funeral da própria democracia.

Civita [...] comparou o conselho proposto pela Fenaj (Federação Nacional dos Jornais) ao antigo Departamento de Imprensa e Propaganda (DIP), órgão encarregado da censura do Estado Novo. Ele afirmou que a proposta atinge a liberdade de imprensa, a livre iniciativa e as instituições democráticas (ANJ defende imprensa livre na constituinte, 1987).

O quadro 01 traz um esquema com os principais vocábulos utilizados pelos três jornais em ambos os períodos (Assembleia Nacional Constituinte e $1^{a}$ Conferência Nacional de Comunicação) na tentativa de associar regulação econômica/social à censura e criar um "clima" de apreensão e perigo para as liberdades de expressão e imprensa diante das propostas de democratização para o setor. 
Quadro 1. Palavras que buscam suscitar o medo da regulação e do controle social dos meios de comunicação - Folha de São Paulo, Jornal do Brasil e Jornal do Commercio

\begin{tabular}{|c|c|}
\hline Termos relativos à Controle Social & $\begin{array}{l}\text { Censura/perigo/ameaça/pretexto/ funeral da } \\
\text { liberdade de expressão/funeral da democracia/ } \\
\text { arapuca/aberração/policiador/temerária }\end{array}$ \\
\hline Termos relativos à regulação & $\begin{array}{c}\text { Cerceamento/ autoritarismo } \\
\text { reacionário/antidemocrático } \\
\text { limites/tutela governamental /retrocesso } \\
\text { atraso /censura/ intervenção } \\
\text { lesivo/artimanha/ provinciano/mal }\end{array}$ \\
\hline $\begin{array}{c}\text { Termos relativos ao "sentimento" } \\
\text { sobre a situação }\end{array}$ & $\begin{array}{c}\text { Medo/terror/ } \\
\text { obscurantista/asustadora }\end{array}$ \\
\hline $\begin{array}{c}\text { Verbos relativos à aplicação de } \\
\text { mecanismos de controle e regulação }\end{array}$ & $\begin{array}{l}\text { Restringir/impor/fiscalizar/alertou } \\
\text { obriguem/esvaziar a imprensa/ } \\
\text { monitorar/intimidar/ preocupam }\end{array}$ \\
\hline
\end{tabular}

Fonte: a autora, mediante pesquisa.

Utilizadas de forma que o raciocínio apresentado se traduza como representação da verdade, na maior parte das vezes, essas escolhas argumentativas não são sequer percebidas. Estes aspectos são particularmente importantes e notórios nos textos chamados de opinião, em especial os editoriais. Importante ressaltar que, segundo autores como Van Dijk (1995), para compreender o lugar que cada empresa de comunicação deseja ocupar no processo de disputa pelo poder e identificar na retórica de seus discursos suas reais intenções no jogo político-financeiro do mercado, basta realizar uma leitura mais atenta de seus editoriais.

No editorial Nenhuma censura (07), por exemplo, a Folha equipara mais uma vez controle e censura e afirma que qualquer lei que vá além do simples ato de garantir o direito negativo à livre expressão é restritiva e antidemocrática.

(07)

Com efeito, a manifestação do pensamento não pode sofrer nenhum tipo de controle "a priori"; ao Estado, cabe apenas punir os abusos praticados. Qualquer variação restritiva desse princípio significa censura, algo intolerável num país que se pretende moderno e democrático.

(Nenhuma censura, 1988).

Estratégias linguísticas que promovam o sentido de impessoalidade e objetividade buscam "mascarar" a existência da subjetividade e da parcialidade no tratamento do objeto em discussão. Portanto, embora o editorial faça uma avaliação axiológica e valorativa dos fatos, o efeito pretendido é que essa apreciação seja compreendida não necessariamente como um ponto de vista, mas como uma consequência inerente aos próprios acontecimentos, como se o que foi dito só pudesse ser dito daquela maneira e não de outra.

Vejamos o exemplo do editorial Voz do atraso (08), do Jornal do Brasil do dia 13 de julho de 1987, que trata da proposta de reservar uma hora por dia do tempo das TVs e rádios para veiculação de notícias relativas ao trabalho dos poderes Executivo e Legislativo em âmbito nacional. Os 
verbos usados na terceira pessoa do singular sem qualquer referência ao $e u$ dão a entender que, o que é tratado no texto não decorre de um posicionamento ideológico, mas de uma consequência da própria realidade.

Onde já se viu regime democrático aceitar herança de ditadura? Os nossos políticos não têm a menor noção de democracia. Se a têm, não a usam: escondem-na. E muito menos de socialismo. O que os políticos administram - com o maior despudor - são seus interesses pessoais. Constituintes ou congressistas são todos os mesmos: querem aparecer, simular trabalho e, no fundo, enganar. Mais nada. (Voz do atraso,1987)

O editorial Liberdade por inteiro (09), publicado no dia 25 de junho de 1987 pela Folha, é outro exemplo de como esse gênero jornalístico busca legitimidade justamente no equilíbrio entre os discursos de engajamento e de distanciamento. Enquanto faz ampla utilização de adjetivos valorativos (perigosa ideia, moralismo doentio e obsoleto, emaranhado daninho e confuso) o texto tenta disfarçar qualquer resquício de um eu acho que ou eu penso que como se o que está escrito fosse um mero reflexo da realidade.

Mesmo que vaga, deve ser bem-vinda a promessa feita pelo deputado Bernardo Cabral de incluir em seu substitutivo uma outra fórmula para o tratamento da liberdade de expressão no país.

$[\ldots]$

Lamentavelmente, não faltam apoios - ainda que inconsistentes - à tese do cerceamento: da perigosa ideia de se criar um "órgão democrático" para análise de casos concretos - passando pelo moralismo doentio e obsoleto - aos argumentos mais sofisticados em favor da restrição ao direito de manifestação do pensamento (frustrantes pela figura de alguns de seus autores), é todo um emaranhado daninho e confuso sobre o sentido político da liberdade de expressão (Liberdade por inteiro, 1987).

Van Dijk (1995) entende que politicamente os editoriais funcionam como "movimentos estratégicos para a legitimação do domínio de uma formação de elite específica ou para manter o equilíbrio de poderes entre diferentes grupos de elite da sociedade" (pp. 205-206). Vejamos:

Veículo e vetor principal e permanente das ideias libertárias e das mais várias expressões do pensamento humano, não é sem motivo que a imprensa tem sido o alvo principal dos Governos totalitários e antidemocráticos. Durante a vigência dos regimes de exceção, a Imprensa se transforma na barricada única não só dos injustiçados, mas também daqueles para quem a liberdade de expressão nada representa. Mas, é justamente nessa aparente contradição onde se pode aferir rigorosamente o papel a ela destinado como instrumento de todas as ideias, guardiã de todas liberdades (Censura, não, 1988).

Percebe-se como o outro (Estado) é mostrado como o tirano, o totalitário a ser enfrentado e ela (a imprensa), como instrumento de todas as ideias, a vítima que de forma heroica vem ao 
longo dos séculos servindo de barricada única não só dos injustiçados, mas também daqueles para quem a liberdade de expressão nada representa. Ela sim, fiel depositária e veiculadora das várias expressões do pensamento humano, única instituição a quem o cidadão pode confiar o seu direito de ser e pensar de forma livre.

Mas, será que o cidadão está mesmo representado no discurso diário da imprensa? Vejamos a seguir.

\subsection{A seleção das fontes: liberdade para alguns}

Uma simples comparação entre a participação ativa das fontes nas matérias analisadas nesse estudo é, por si só, uma forte evidência da parcialidade praticada pelos jornais quando o assunto em pauta é o respeito à liberdade de expressão dos cidadãos. Como podemos ver no quadro 02, ao observar a quantidade de inserções dos "tipos" de fontes consultadas pelos veículos nas matérias que discutiam o futuro da comunicação no país, pode-se constatar que em nenhuma ocasião o "cidadão comum" é chamado a opinar. Não há, em nenhum dos três jornais analisados, a participação direta ou indireta do ator que deveria ser protagonista nessa discussão.

Quadro 2. Número de inserções por "tipo" de fonte

\begin{tabular}{|c|c|c|c|c|c|c|}
\hline & \multirow[b]{3}{*}{ Jornal } & \multicolumn{5}{|c|}{ Inserções } \\
\hline & & & Fontes & & & Outros \\
\hline & & $\begin{array}{c}\text { Fontes } \\
\text { empresariado }\end{array}$ & $\begin{array}{c}\text { movimentos } \\
\text { sociais }\end{array}$ & Parlamentares & $\begin{array}{l}\text { Cidadão } \\
\text { "comum", }\end{array}$ & $\begin{array}{l}\text { (intelectuais/ } \\
\text { autoridades) }\end{array}$ \\
\hline $\begin{array}{c}\text { Constituinte } \\
\text { (jan/87 a dez/88) }\end{array}$ & $\begin{array}{l}\text { Folha de } \\
\text { São Paulo }\end{array}$ & 15 & 07 & 32 & 0 & 18 \\
\hline $\begin{array}{c}\text { Confecom } \\
\text { (ago/09 a mar/10) }\end{array}$ & & 03 & 02 & 04 & 0 & 9 \\
\hline $\begin{array}{c}\text { Constituinte } \\
\text { (jan/87 a dez/88) }\end{array}$ & $\begin{array}{c}\text { Jornal do } \\
\text { Brasil }\end{array}$ & 05 & 01 & 09 & 0 & 0 \\
\hline $\begin{array}{c}\text { Confecom } \\
\text { (ago/09 a mar/10) }\end{array}$ & & 0 & 0 & 0 & 0 & 0 \\
\hline $\begin{array}{c}\text { Constituinte } \\
\text { (jan/87 a dez/88) }\end{array}$ & $\begin{array}{l}\text { Jornal do } \\
\text { Commercio }\end{array}$ & 04 & 01 & 21 & 0 & 01 \\
\hline $\begin{array}{c}\text { Confecom } \\
\text { (ago/09 a mar/10) }\end{array}$ & & 0 & 0 & 0 & 0 & 0 \\
\hline
\end{tabular}

Fonte: a autora, mediante pesquisa

Nos 26 textos encontrados na Folha de São Paulo que tratavam das discussões na Constituinte e que "ouviam" algum tipo de fonte, em 15 situações são ouvidos entrevistados ligados a associações que reúnem os empresários do setor e em apenas 07 ocasiões as associações que não são diretamente ligadas aos empresários, como é o caso da Federação Nacional dos Jornais - Fenaj (que historicamente defende a regulação econômica para o setor midiático), possuem espaço no texto. Outros movimentos sociais não aparecem em nenhum dos textos. No Jornal do Brasil a 
proporção é semelhante: em 08 matérias encontradas o empresariado foi ouvido em 05 momentos e fontes com posicionamentos opostos em apenas uma ocasião. No jornal do Commercio, nos 20 textos que tratam do assunto, fontes contrárias à posição do jornal apareceram somente em 07 ocasiões.

A preferência por fontes ligadas ao empresariado e o uso de verbos e expressões que denotam distanciamento e discordância do que é dito pelos poucos entrevistados ligados às organizações sociais, são recursos que, pela frequência de utilização, nos levam a constatar a maneira parcial e distorcida com que a grande mídia trata os temas ligados à liberdade de expressão. A produção de notícias sobre a comunicação no país se constrói, portanto, sob discursos de ausências. Na deslegitimação discursiva dos que pensam diferente dela própria, a grande mídia segue publicando a posição de um segmento específico como se pública fosse, ampliando a fenda entre sociedade civil e poder público e impedindo o debate dialógico, próprio das democracias mais avançadas.

\section{Conclusão}

No conteúdo publicado pelos principais jornais do país nos períodos em que o debate sobre a liberdade de expressão foi mais acentuado, foi possível perceber claras tentativas de direcionar o discurso no sentido de transferir o direito inviolável do cidadão à livre expressão para os veículos de comunicação. Embora sejam identificadas divergências pontuais na postura dos três veículos avaliados, elas assumiram níveis irrisórios. Alinhados por interesses semelhantes, todos pareceram usar as mesmas lentes no momento de observar e interpretar os acontecimentos ligados ao tema em questão.

As falhas na exatidão do discurso, o silenciamento das ideias contra hegemônicas, a interdição do debate público, os laços com o liberalismo e a promoção de uma espécie de amnésia sobre seu próprio passado ${ }^{1}$ variaram apenas na forma de abordagem de jornal para jornal e de período para período.

Apesar de terem acontecido com quase 25 anos de diferença, a cobertura que os três jornais fizeram dos dois eventos foco de nossa observação foram bem semelhantes: os atores usados como fontes são basicamente os mesmos, o fantasma da censura igualmente "acionado" contra qualquer reflexão crítica sobre democratização/regulação econômica e a proposital confusão entre liberdade de expressão, liberdade de imprensa e liberdade empresarial permaneceu sendo a fórmula mais eficaz para desorientar o público e defender o status quo midiático.

Assim se construíram e se constroem os mitos da liberdade de expressão como proteção do indivíduo contra o Estado e da censura como um tipo de intervenção que só nesse Estado tem origem. Uma discursividade monológica que ao longo de anos conseguiu atrofiar tal discussão na

1. A grande imprensa procurar fazer esquecer que ela cresceu na e com a ditadura, esconder os inúmeros papéis antidemocráticos que exerceu durante vários eventos da história do país. No texto Imprensa e democracia, publicado na Folha de S. Paulo no dia 03/06/2012, Jânio de Freitas afirma: "Está na história: assim como a imprensa pode tirar a Constituição do papel, tira também o papel da Constituição, na sociedade e no país. A força agitadora para a preparação do golpe de 64 foi a imprensa. Com agitação diuturna. Todos os demais agentes foram insignificantes em comparação com a imprensa, e dependentes dela. Quando ganharam significação, já a imprensa e o golpismo estavam muito à sua frente, vindo apenas a aproveitar, para a consumação do seu propósito, os múltiplos e estimulantes erros da chamada "esquerda"”. (FSP, 03/06/2012 disponível em www1.folha.uol.com.br/fsp/poder/46597-imprensa-e-democracia.shtml) 
esfera pública e interditar enunciados indispensáveis para a promoção de uma mobilização social ampla que permitisse o acesso do atore por quem e para quem a comunicação mediática deveria existir: o cidadão.

\section{Bibliografia}

(2010, março 2). Fórum critica "controle social"da mídia. Folha de São Paulo.

(2010, janeiro 18). No vácuo de Lula. Folha de São Paulo.

(1988, agosto 9). Censura, não. Jornal do Commercio

(1988, fevereiro 6). Nenhuma Censura. Folha de São Paulo.

(1987, novembro 7). ANJ reivindica ampla liberdade para a imprensa. Jornal do Brasil.

(1987, julho 25). Liberdade por inteiro. Folha de São Paulo.

(1987, julho 13). Voz do atraso. Jornal do Brasil.

(1987, junho 5). Projeções do atraso. Jornal do Brasil.

(1987, abril 2). ANJ defende imprensa livre na constituinte. Jornal do Brasil.

Bourdieu, P. (2003). O poder simbólico. Rio de Janeiro: Bertand Brasil.

Carvalho, L. B. (2012). Os meios de comunicação, a censura e a regulação de conteúdo no Brasil: aspectos jurídicos e distinções conceituais. Revista de Direito, Estado e Telecomunicaçoes, $4(1), 51-82$.

Chauí, M. (04 de setembro de 2012). O poder da mídia. Fonte: Observatório da Imprensa: www.observatoriodaimprensa.com.br/news/view/_ed710_o_poder_da_midia

Declaração universal dos direitos do homem. (1948, 10 de dezembro). Fonte: pcp: www.pcp.pt/ac tpol/temas/dhumanos/declaracao.html

Dijk, T. A. (1995). Racismo y análisis crítico de los medios. Barcelona: Bosch.

Guareschi, P. A. (2013). O direito humano à comunicação: pela democratização da mídia. Petrópolis - RJ: Vozes.

Lima, V. A. (2009). Liberdade de expressão x liberdade de imprensa. São Paulo: Publisher.

Lima, V. A. (2008, 18 de agosto). A comunicaçao na Constituinte de 87/88. Fonte: Observatório da Imprensa: http://observatoriodaimprensa.com.br/caderno-da-cidadania/a-comunicacao-na -constituinte-de-8788/

NaÇOes UnidAs (1945, 26 de junho). Carta das naçoes unidas. https://nacoesunidas.org/carta/

Pacto internacional de direitos civis e políticos. (1966, 16 de dezembro). Fonte: refugiados.net: www.refugiados.net/cid_virtual_bkup/asilo2/2pidcp.html

Pieranti, O. P. (2008). Censura versus regulação de conteúdo: em busca de uma definição conceitual. In P. E. Enrique Saraiva, Democracia e regulação dos meios de comunicação de massa (p. 139). Rio de Janeiro: FGV. 